

\title{
Pembuatan Video Bumper Logo 3D Animasi Almados Buana Utama Dengan Adobe After Effect
}

\author{
Erick Febriyanto $^{1}$ \\ Wahyu Hidayat ${ }^{2}$ \\ Rendy Angga Saputra ${ }^{3}$ \\ Jurusan Sistem Informasi, STMIK Raharja, Tangerang \\ Email :erick@raharja.info ${ }^{1}$,wahyu.hidayat@raharja.info ${ }^{2}$,rendy.angga @raharja.info ${ }^{3}$
}

\begin{abstract}
ABSTRAK
Perkembangan dunia terhadap multimedia sangatlah pesat dan membuat banyaknya permintaan terhadap desainer, animator, editor dan lainnya. Terutama dibidang animator dimana di Indonesia sangatlah langka untuk menemukan seorang animator. Tujuan penulisan ini agar masyarakat dapat tertarik untuk menjadi seorang animator walaupun hanya sekedar membuat animasi ringan. Namun dikarenakan upah yang cukup rendah yang biasa diberikan oleh perusahaan di Indonesia terhadap animator, membuat minat anak-anak bangsa untuk menjadi seorang animator sangat rendah juga. Adapun hal yang berkaitan dengan tema jurnal ini yaitu logo yang memiliki arti sebagai perwakilan dari sebuah perusahaan, lembaga, produk dan hal lainnya yang dijadikan sebagai pengganti dari nama sebenarnya agar mudah di ingat. Animasi itu memiliki arti benda yang bergerak dari posisi awal ke posisi berikutnya, dengan bantuan frame per frame animasi dapat diciptakan. Animasi sangatlah susah untuk dibuat, dikarenakan kita perlu menguasai dasar animasi yang berawal dari gambar dan hanya sedikit orang yang dapat menggambar dengan bagus juga cepat. Hal lainnya yang membuat animasi susah adalah aplikasi atau software yang digunakan sangatlah rumit dan guru - guru animasi yang langka untuk ditemukan di Indonesia. Maka jika kita belajar dan memahami animasi akan menjadi peluang besar bagi kita untuk bekerja sebagai animator. Walaupun kita hanya pemula dan hanya belajar lewat internet, jika karya kita dilihat orang - orang maka disitulah kebanggaan anda sebagai animator mulai terasa. Untuk membuat sebuah animasi seperti yang dibicarakan diatas, memerlukan metode obvservasi, analisa, produksi dan implementasi agar animasi yang dibuat dapat menarik perhatian masyarakat.
\end{abstract}

Kata Kunci: Design 3D, Logo 3D, Animasi 3D, After effect

31| Erick, Wahyu, Rendy - Pembuatan Video Bumper Logo 3D Animasi ..... 


\section{ABSTRACT}

The development of multimedia is very rapid and making the world in needs of designers, animators, editors and many more. Especialy in the field of animators where in Indonesia is very rare to find an animator. The purpose of this writing so that people will be interested in becoming an animator even if just make a light animation. However, due to low wages commonly given by the companies in Indonesia to the animators make the nation's youngster interest to becoming an animator is low as well. As for the matters relating to the theme of this journal is a logo that has the meaning as a representative of a company, institutions, products and other things that serve as a subtitute of the real name for easy to remember. Animation has a meaning of a moving object that move from its inital place to the next place, with the help of frame per frame animation can be created. Its hard to make an animation, because we need to know the basic animation from drawing and only few people that can draw well and also fast. Another things that made animation hard to make is the aplication or the software that being used is complicated and the animation teachers are rare to find in Indonesian. So if we learn and understand animation will give us a big chance to work as animator. Even if we only a beginner and only learning through internet, if our creation being seen by people and they are amazed, then thats where your pride as animator begin to feel. To made an animation as discussed above, we need obvervation method, analysis, production and implementation so the animation we made would attract people's attention.

Keywords: Design 3D, Logo 3D, Animasi 3D, After Effect

\section{PENDAHULUAN}

Perkembangan teknologi sekarang ini sangatlah pesat yang menimbulkan banyaknya peluang untuk berkarya. Terutama pada bidang promosi, dimana kita tidak perlu lagi tatap muka dengan calon customer melainkan menggunakan teknik promosi berupa video iklan yang dapat ditonton oleh banyak orang. Dengan adanya iklan ini orang dapat dengan mudah mempromosikan barang atau jasanya tanpa harus turun tangan kejalan. Keadaan yang demikian, dimana sebuah teknologi mampu merubah sesuatu yang belum tentu dapat dilakukan menjadi sebuah kenyataan.

Secara umum, iklan berwujud penyajian informasi nonpersonal tentang suatu produk, merek, perusahaan, atau toko yang dijalankan dengan kompensasi biaya tertentu. Maka dari 
itu, iklan berupa proses komunikasi yang memiliki tujuan membujuk atau menarik orang banyak untuk mengambil tindakan yang menguntungkan pihak yang membuat iklan.

Animasi 3D merupakan penciptaan gambar bergerak dalam ruang digital 3 dimensi. Animasi 3D merupakan jantung dari game dan virtual reality, tetapi biasanya animasi 3D juga digunakan dalam presentasi grafis untuk menambahkan efek visual ataupun film.

Bumper adalah animasi pembuka atau penutup dalam sebuah program video yang merupakan animasi pendek yang menggambarkan identitas sebuah acara atau instansi. Dengan adanya bumper tersebut acara atau instansi tersebut akan mudah dipahami oleh pemirsa tanpa perlu penjelasan yang panjang lebar. Bumper dibagi menjadi 2 kategori. Bumper in yaitu signature untuk masuk ke segmen dalam program video. dan bumper out yaitu signature tanda segmen itu berakhir. atau lebih jelasnya dalam setap acara TV berlangsung selalu diselingi oleh beberapa iklan, jeda antara acara TV dan iklan itulah bumper muncul.

\section{PERMASALAHAN}

Indonesia adalah salah satu negara yang memiliki prosentase terendah dalam bidang pekerjaan animator nya dengan prosentase sekitar $6.6 \%$. Hal ini dipicu oleh susah nya mencari guru atau master dalam bidang animasi itu sendiri. Harga sekolah animasi yang cukup mahal pun menjadi salah satu penghambat minat orang Indonesia untuk berkarya di bidang animasi. Dan tidak hanya itu saja, minat lulusan SMK maupun SMA pun jarang yang memilih untuk menjadi animator dikarenakan dibutuhkannya skill atau talent dari setiap individu.

Ditambah lagi kita berada di zaman digital, zaman yang serba berkaitan dengan teknologi. Dengan perkembangan pesat terhadap teknologi ini membuat banyaknya lulusan yang diwajibkan bisa mengoprasikan komputer. Namun tidak banyak yang mengerti mengoprasikan software tertentu seperti Auto Desk Maya, Blender, Adobe After Effect dan software lainnya ynag bisa membuat animasi. Bahkan mereka yang berminat di dunia animasi lebih banyak yang belajar sendiri lewat internet. 
Genre Film di Indonesia pun menjadi salah satu penyebab sedikitnya minat orang - orang Indonesia untuk terjun di dunia animasi. Contohnya seperti grafik dibawah ini :

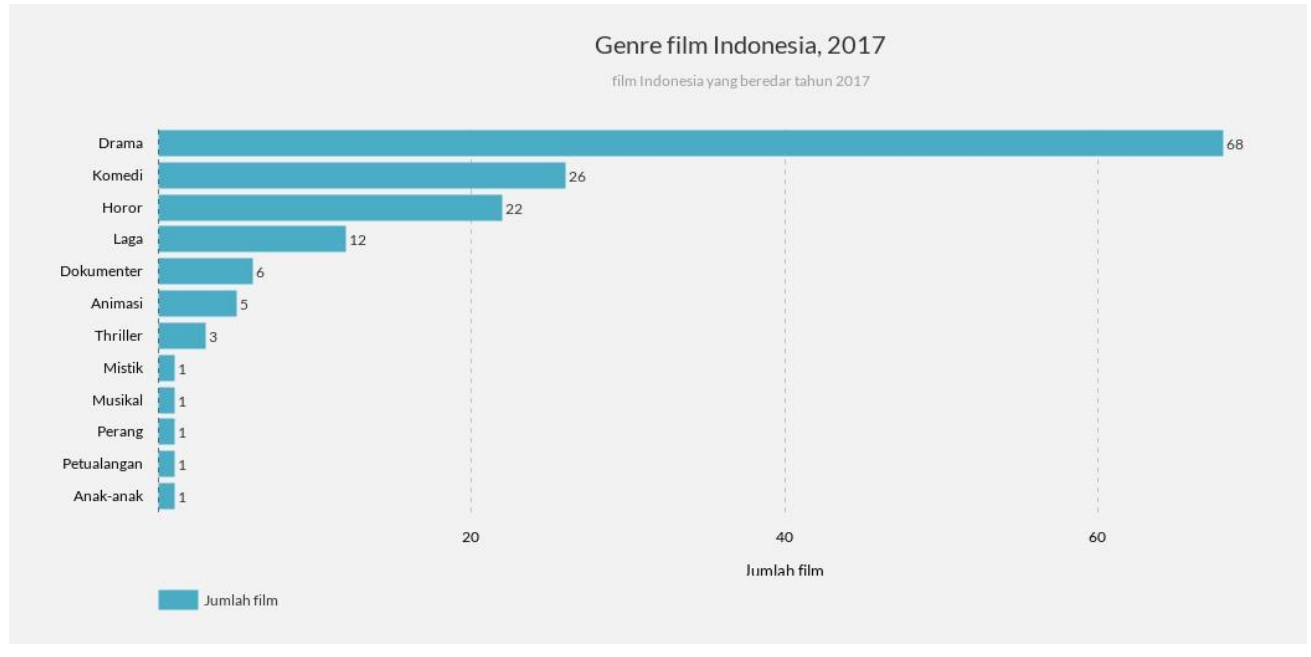

Gambar 1. Grafik Genre Film di Indonesia

Bisa dilihat bahwa orang Indonesia lebih banyak memproduksi film bergenre drama dibanding dengan animasi dikarenakan animator yang langka. Dan salah satu penyebab dikitnya produksi film animasi dikarenakan susahnya mencari orang animator yang handal di Indonesia, rata - rata animator yang handal pastinya bekerja diluar Negri dikarenakan gaji yang lebih besar. Ditambah lagi pembuatan animasi sangatlah susah dan memakan waktu yang cukup lama jika hanya dikerjakan oleh sedikit orang.

\section{METODE PENELITIAN}

1. Observasi, yaitu cara untuk mendapatkan data dengan jalan pengamatan secara langsung ke lokasi.

2. Analisa, setelah melakukan observasi selanjutnya menganalisa data yang didapat.

3. Produksi, selanjutnya melakukan pengerjaan pembuatan componen awal dari logo Almados yang sudah ada dan di re-tracing kebentuk animatedable pada Adobe Photoshop, lalu masuk ke proses animasi di Adobe After Effect.

4. Implementasi, Setelah melakukan proses pembuatan video bumper logo 3D animasi dengan Adobe After Effect cc 2015.

34| Erick, Wahyu, Rendy - Pembuatan Video Bumper Logo 3D Animasi ..... 
Berikut ini adalah daftar literature review yang digunakan dalam penelitian ini:

1. Penelitian yang dilakukan oleh Novan Andre Prastyo dengan judul "Pembuatan Video Profil Tiga Dimensi (3D) Sentra Ponsel Kudus" Penelitian ini membahas tentang pembuatan video profil 3D atau company profile 3D.

2. Penelitian yang dilakukan oleh Sri Maryati, Bambang Eka Purnama dengan judul "Pembuatan Video Profil Sekolah Menengah Pertama Negeri 4 Polokarto Kabupaten Sukoharjo Dengan Menggunakan Komputer Multimedia” Penelitian ini membahas tentang pembuatan video profil SMP Negri 4 Polokarto.

3. Penelitian yang dilakukan oleh Syaiful Nurudin, Nugroho Agung Prabowo dengan judul "Pembuatan Video Profile Tiga Dimensi (3D) Octrash Gemolong Kabupaten Sragen" Penelitian ini membahas tentang pembuatan video profil 3D atau company profile 3D.

4. Penelitian yang dilakukan oleh Jiadis Suciati Sholifah, Hestiasari Rante, Dwi Susanto dengan judul "IMPLEMENTASI TEKNIK MOTION GRAPHICS PADA PEMBUATAN PROFIL MULTIMEDIA BROADCASTING” Penelitian ini membahas tentang teknik pembuatan motion grafik 3D.

5. Penelitian yang dilakukan oleh Jodi Rinaldi, A.M. Rumagit, A.S.M. Lumenta, A.P.R. Wowor, dengan judul "Perancangan Tutorial Penerimaan Mahasiswa Baru Universitas Sam Ratulangi Berbasis Animasi 3D” Penelitian ini membahas tentang pembuatan animasi tutorial penerimaan mahasiswa baru.

6. Penelitian yang dilakukan oleh Muhamad Z. Buchari, Steven R. Sentinuwo, Oktavian A. Lantang dengan judul "Rancang Bangun Video Animasi 3 Dimensi Untuk Mekanisme Pengujian Kendaraan Bermotor di Dinas Perhubungan, Kebudayaan, Pariwisata, Komunikasi dan Informasi" Penelitian ini membahas tentang pembuatan video animasi untuk pengujian mekanisme kendaraan bermotor.

7. Penetilian yang dilakukan oleh Hendro Saputra Suratinoyo, Hans Wowor, Jimmy Robot, Stanley Karouw dengan judul “CERITA RAKYAT DAERAH MINAHASA : IMPLEMENTASI SHORT FILM ANIMASI 3D" Penelitian ini membahas tentang pembuatan short film animasi 3D cerita rakyat daerah minahasa.

35| Erick, Wahyu, Rendy - Pembuatan Video Bumper Logo 3D Animasi ..... 
8. Tiara, K., Nurhaeni, T., \& amalia, I. (2016). Penerapan Viewboard GO+ Berbasis Yii Sebagai Media Monitoring Pembayaran Mahasiswa, Technomedia Journal, 1(1), 6577.

9. Yusup, M., Aini, Q., \& Pertiwi, K. (2016). Media Audio Visual Menggunakan Videoscribe Sebagai Penyajian Informasi Pembelajaran Pada Kelas Sistem Operasi, Technomedia Journal, 1(1), 126-138.

Setelah melakukan peninjauan dari 9 Literature Review yang ada, telah banyak penelitian mengenai pemanfaatan video 3D animasi sebagai media pemasaran dan informasi, oleh karena itu penulis membahas hal "Pembuatan Video bumper logo 3D animasi Almados Buana Utama dengan After Effect" agar yang menonton video bumper ini dapat tertarik dengan animasi 3D yang dibuat.

\section{HASIL DAN PEMBAHASAN}

\section{Analisa Permasalahan}

Analisa digunakan dengan metode SWOT pada video Bumper logo 3D animasi dengan mengidentifikasi faktor internal dan external yang diperoleh melalui observasi yang dilakukan dengan mengamati secara langsung perkembangan video bumper pada iklan iklan yang ada.

identifikasi faktor internal dan eksternal yang dirumuskan dalam menganalisa pengetahuan video bumper logo $3 \mathrm{~d}$ animasi sebagai berikut.

1. Strength ( Kekuatan )

a. Video animasi sangat digemari banyak orang terutama oleh remaja dan kanak - kanak.

b. Tingginya permintaan atas animator di Indonesia.

2. Weaknesses ( Kelemahan )

a. Susahnya mencari panutan referensi local ( animator local)

3. Opportunities ( Peluang)

a. Animasi di Indonesia sangat disupport oleh pemerintah Indonesia.

36| Erick, Wahyu, Rendy - Pembuatan Video Bumper Logo 3D Animasi ..... 
b. Banyaknya perusahaan local yang membutuhkan video bumper animasi untuk media introducing mereka.

c. Animator sangat sedikit di Indonesia sekitar 6,6\% jadi saingan pun juga dikit.

4. Thearts ( Ancaman )

a. Semangkin berkembangnya zaman maka semakin berkembangnya juga orang - orang yang mulai memahami animasi dan menjadi rival.

b. Banyaknya animator company dari luar yang lebih kompetent.

\section{Pemecahan Masalah}

Setelah mengamati dan meneliti dari beberapa permasalahan yang terjadi terdapat pemecahan masalah yaitu dengan cara membuat sebuah animasi 3D yang menarik untuk ditonton dan menguploadnya melalui sosial media seperti youtube yang saat ini digemari oleh kalangan anak muda maupun dewasa. Hal ini akan mempermudah dalam mempromosikan Video Bumper logo 3D animasi Almados.

\section{Tahap Implementasi}

\section{a. Tahap Observasi}

Melakukan pengamatan terhadap video - video iklan apa saja yang menggunakan bumper animasi.

\section{b. Tahap pra produksi}

Pra produksi adalah persiapan awal dengan menggunakan metode analisa masalah. Pengaplikasian belum dilakukan namun persiapan yang dibutuhkan sudah direncanakan. Dalam persiapan penelitian terlebih dahulu mengidentifikasikan masalah dengan memahami apakah masalah yang didapat dengan aplikasi multimedia.

\section{c. Perancangan Storyboard}

storyboard adalah kumpulan gambar alur cerita yang diuraikan dan disusun sedemikian rupa sehingga dapat diaplikasikan dalam bentuk video bumper. Gambaran sederhana video bumper logo 3d animasi Almados.

\section{d. Tahap produksi}

1. Pembuatan ulang logo yang sudah ada untuk dijadikan hitam pekat agar bisa dianimasikan dengan menggunakan Adobe Photoshop.

2. Merubah logo yang tadinya dua dimensi menjadi tiga dimensi dengan bantuan Plugin copilot $3 D$ element. 
3. Memberikan lightning agar ketika di animasikan terlihat nyata dengan bantuan $3 r d$ party magic bullet looks effect.

4. Memulai animasi sesuai kemauan client

5. Penambahan Audio agar bumper yang telah dianimasikan menjadi sempurna.

6. Finishing dengan merender hasil animasi yang telah dibuat.

\section{Tampilan Program}

Berikut adalah screenshoot dari video bumper yang dibuat, sesuai dengan storyboard yang telah dikumpulkan seperti gambar - gambar dibawah ini :

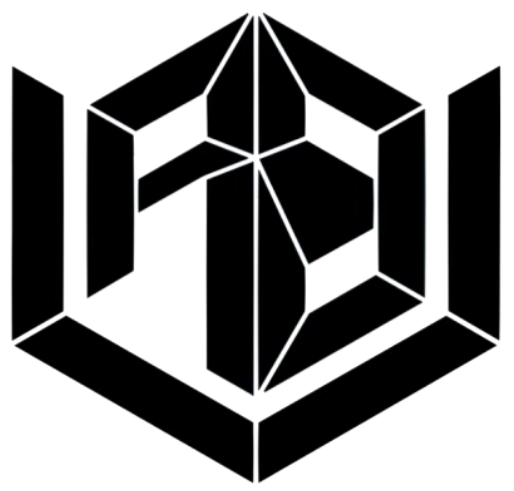

Gambar 2. Bentuk Logo Original Almados

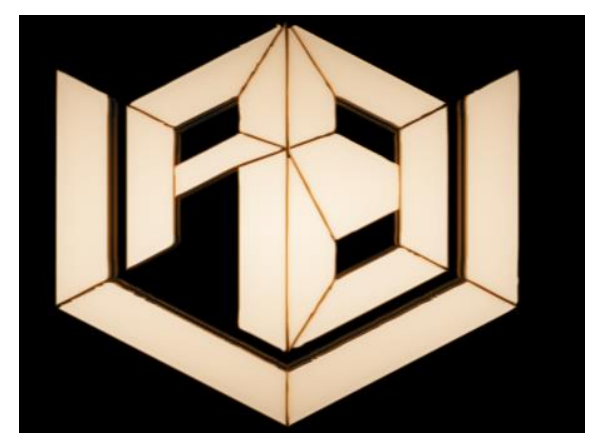

Gambar 3. Logo Almados 3d dengan posisi front view setelah jadi 


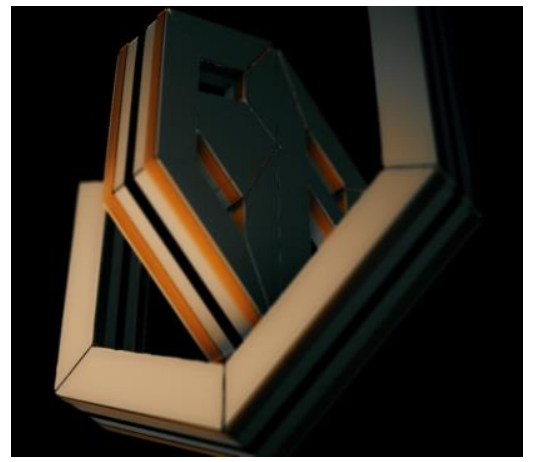

Gambar 4. Logo Almados 3d dengan posisi bottom view setelah jadi

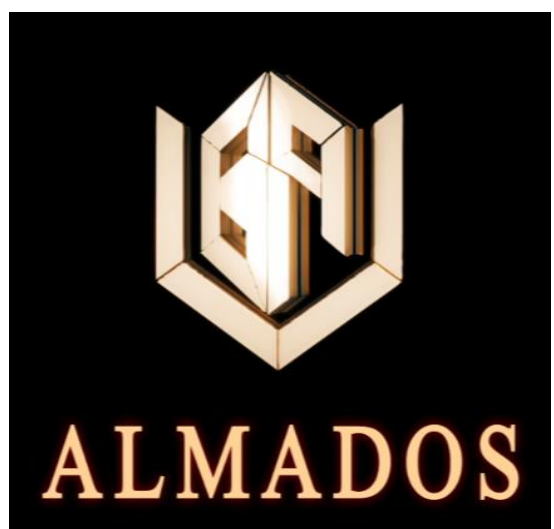

Gambar 5. Logo almados serta text "Almados" di akhir scene.

Adapun Proses video editing dan animating dengan menggunakan Adobe After Effect cc 2015 sebagai berikut :

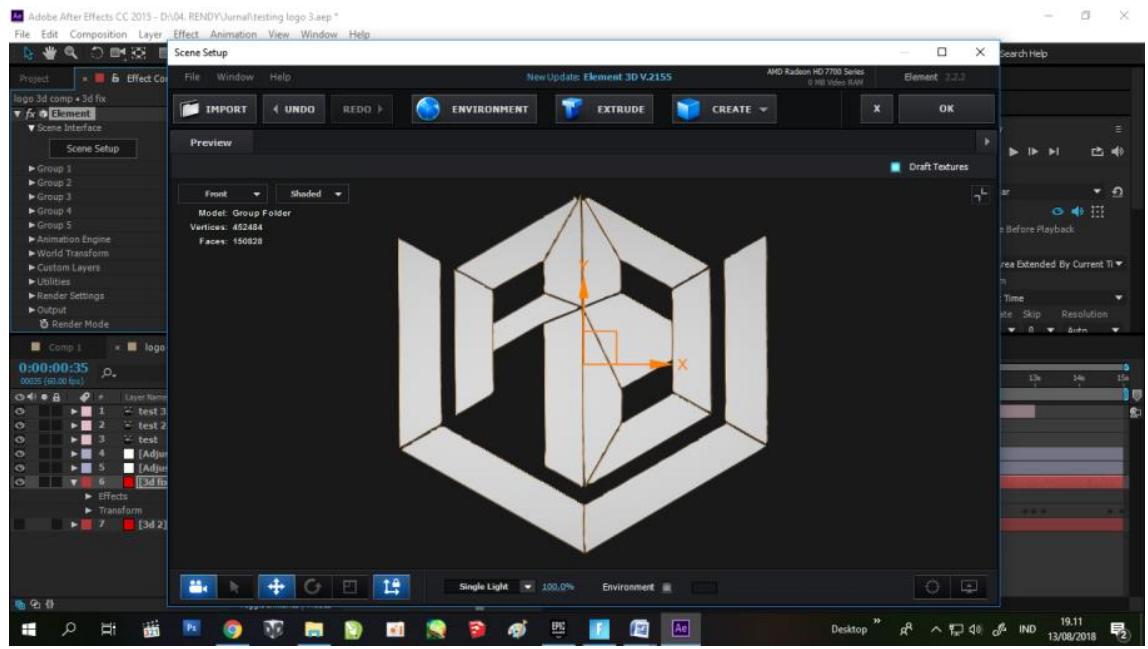

39| Erick, Wahyu, Rendy - Pembuatan Video Bumper Logo 3D Animasi ..... 
Gambar 6. Membuat Ulang Logo Almados di After Effect untuk dijadikan 3D

Pada tahap ini kita menggunakan masking pada gambar logo yang telah di import agar dapat di baca oleh plugin element 3d. Kebetulan logo tersebut memiliki 14 bagian terpisah untuk di masking 1 per 1 agar nantinya dapat digerakan secara bersamaan. Setelah selesai di masking baru kita dapat melanjutkan ke tahap berikutnya.

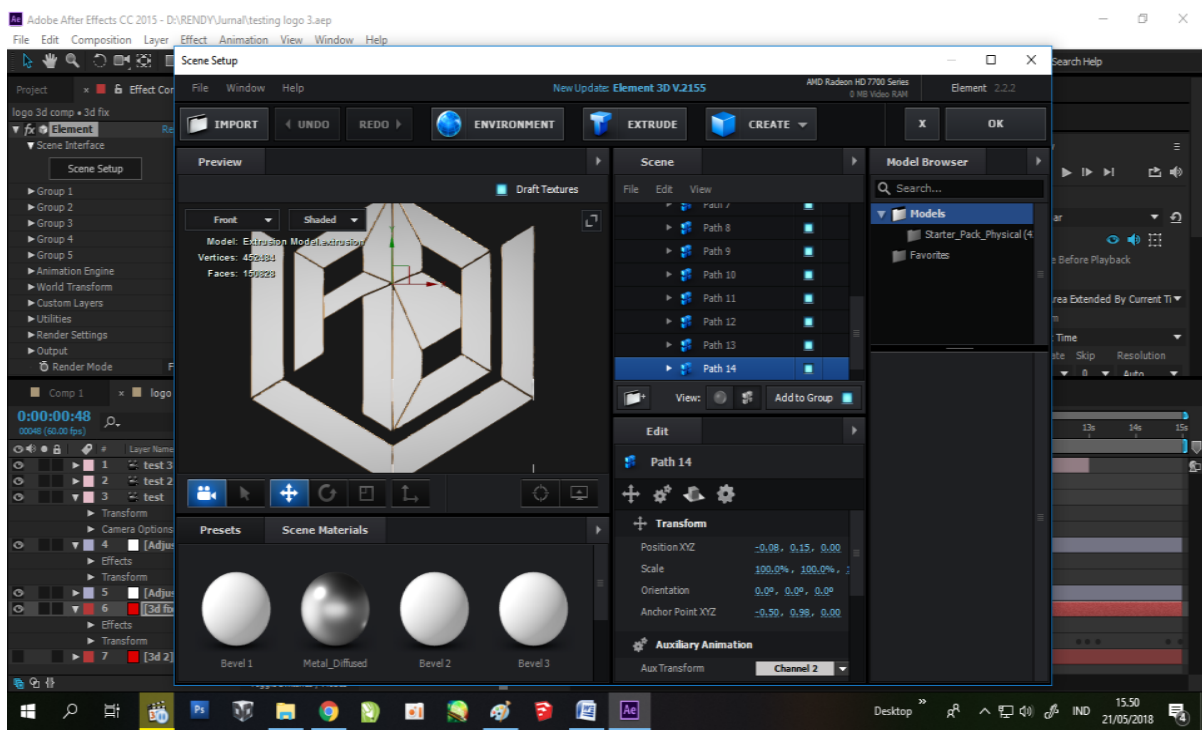

Gambar 7. Proses pembuatan 3D logo Almados dengan video copilot element 3D

Setelah logo di masking kita dapat memulai proses Extrude ( pembuatan 3d) dengan software video copilot element $3 d$, bisa dilihat ada 14 path yang dapat kita edit di plugin ini. Masing masing path kita extrude dengan ukuran yang sama dan jadilah bentuk $3 d$ nya.

40| Erick, Wahyu, Rendy - Pembuatan Video Bumper Logo 3D Animasi ..... 


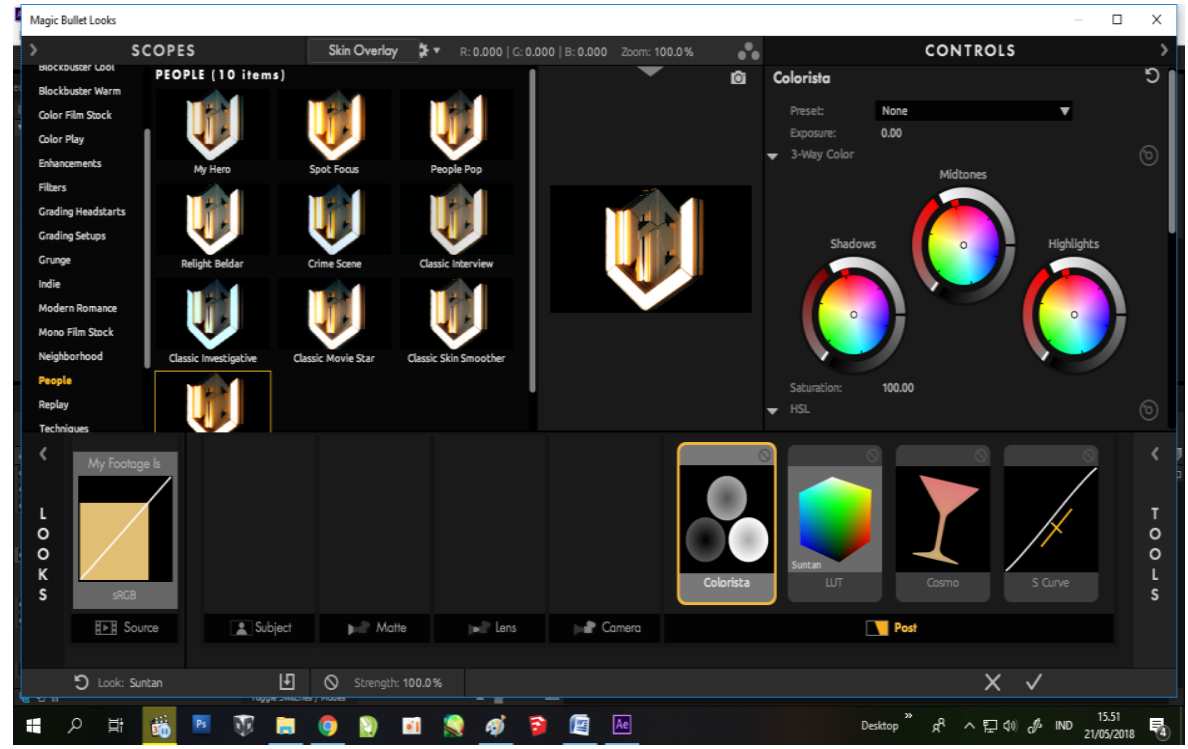

Gambar 8. Proses pemberian lightning dengan bantuan Magic bullet looks

Setelah bentuk $3 d$ sudah dibuat kita perlu menambahkan warna dan pencahayaan ( lightning ) pada logo tersebut. Saya menggunakan plugin magic bullet looks, dikarenakan mudah penyesuaiannya untuk siapa saja.

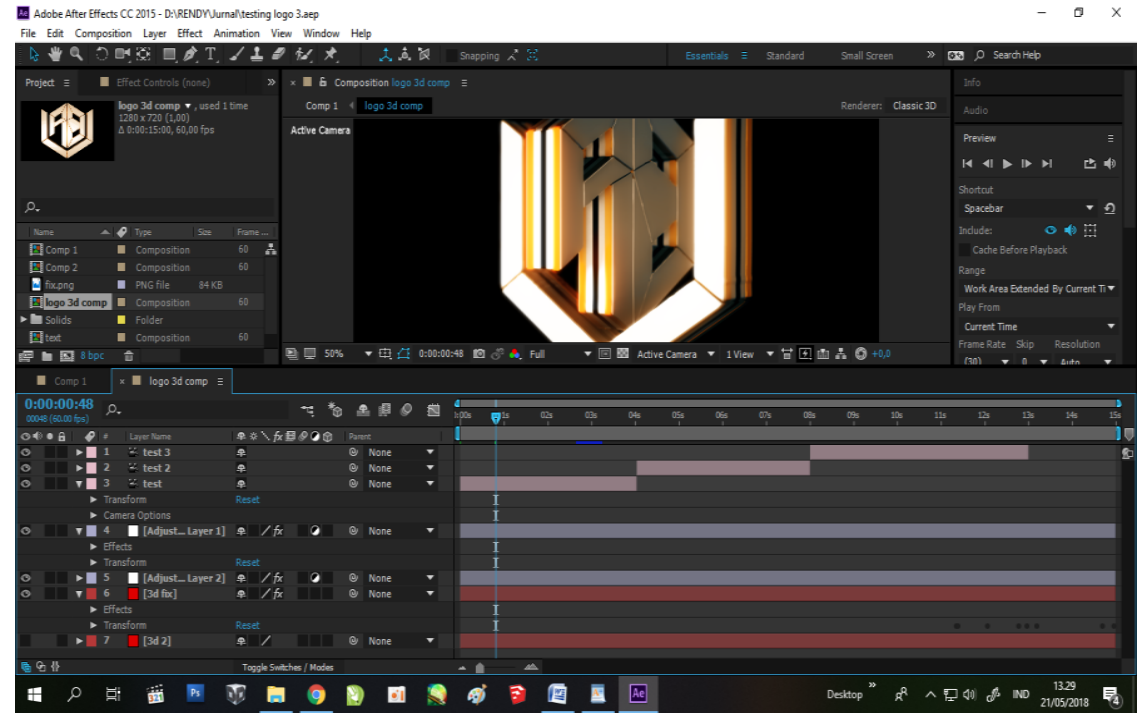

Gambar 9. Proses animating logo Almados

Setelah visual telah dibuat pastikan kita menambahkan audio agar karya kita komplit. Karena audio lah yang membuat visual terasa hidup walaupun hanya sebatas 2D atau 3D yang dilihat dari layar monitor atau TV. 


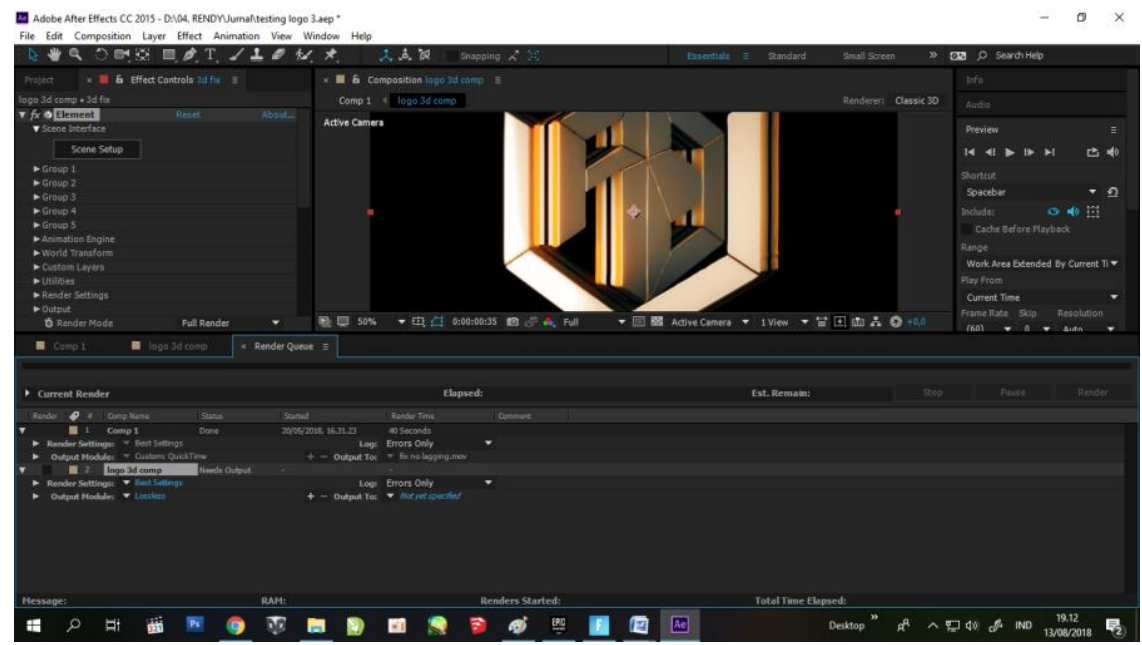

Gambar 10. Proses Rendering

\section{KESIMPULAN}

Berdasarkan analisa yang telah dilakukan dan telah sesuai dengan apa yang ingin ditampilkan pembuatan Video Bumper Logo 3D animasi dengan menggunakan Adobe After effect cc 2015 dapat diambil kesimpulan yaitu hasil animasi yang dibuat Logo 3D animasi sebagai alat intro dan outro company profil maupun iklan dalam bentuk animasi sangatlah langka, dan menjadi peluang bagi kami para animator.

\section{SARAN}

Berdasarkan pembahasan yang telah diuraikan sebelumnya, penulis dapat menyimpulkan saran sebagai berikut Video Bumper Logo 3D animasi dapat menarik perhatian orang hanya dari intro nya saja. Maka dengan demikian animasi merupakan daya tarik yang cukup besar tentunya dengan effort yang cukup besar juga.

\section{DAFTAR PUSTAKA}

[1] Novan Andre Prastyo, (2010). Pembuatan Video Profil Tiga Dimensi (3D) Sentra Ponsel Kudus. Journal Speed - Sentra Penelitian Engineering dan Edukasi - Volume 2 No $4-2010$.

42| Erick, Wahyu, Rendy - Pembuatan Video Bumper Logo 3D Animasi ..... 
[2] Sri Maryati, Bambang Eka Purnama (2013). Pembuatan Video Profil Sekolah Menengah Pertama Negeri 4 Polokarto Kabupaten Sukoharjo Dengan Menggunakan Komputer Multimedia. Journal Speed - Sentra Penelitian Engineering dan Edukasi Volume 5 No $1-2013$.

[3] Syaiful Nurudin, Nugroho Agung Prabowo (2010). Pembuatan Video Profile Tiga Dimensi (3D) Octrash Gemolong Kabupaten Sragen. Journal Speed - Sentra Penelitian Engineering dan Edukasi - Volume 2 No 1 - 2010.

[4] Jiadis Suciati Sholifah, Hestiasari Rante, Dwi Susanto. IMPLEMENTASI TEKNIK MOTION GRAPHICS PADA PEMBUATAN PROFIL MULTIMEDIA BROADCASTING. PENS-ITS surabaya 2011.

[5] Jodi Rinaldi, A.M. Rumagit, A.S.M. Lumenta, A.P.R. Wowor (2012). Perancangan Tutorial Penerimaan Mahasiswa Baru Universitas Sam Ratulangi Berbasis Animasi 3D. E-Journal Teknik 2012.

[6] Muhamad Z. Buchari, Steven R. Sentinuwo, Oktavian A. Lantang (2015). Rancang Bangun Video Animasi 3 Dimensi Untuk Mekanisme Pengujian Kendaraan Bermotor di Dinas Perhubungan, Kebudayaan, Pariwisata, Komunikasi dan Informasi. E-journal Teknik Informatika, volume 6, No. 1 (2015).

[7] Hendro Saputra Suratinoyo, Hans Wowor, Jimmy Robot, Stanley Karouw (2013). CERITA RAKYAT DAERAH MINAHASA : IMPLEMENTASI SHORT FILM ANIMASI 3D. E-Journal vol.2, no.2 (2013).

[8] Tiara, K., Nurhaeni, T., \& amalia, I. (2016). Penerapan Viewboard GO+ Berbasis Yii Sebagai Media Monitoring Pembayaran Mahasiswa, Technomedia Journal, volume $1(1), 65-77$.

[9] Yusup, M., Aini, Q., \& Pertiwi, K. (2016). Media Audio Visual Menggunakan Videoscribe Sebagai Penyajian Informasi Pembelajaran Pada Kelas Sistem Operasi, Technomedia Journal, volume 1(1), 126-138.

43| Erick, Wahyu, Rendy - Pembuatan Video Bumper Logo 3D Animasi ..... 